\title{
Two-Dimensional Analysis Of Flow Field And Associated Scour Parameters At Downstream Of Weir With And Without Sloping Apron
}

\author{
R. Karthik, U. Kumar, and A.K. Barbhuiya
}

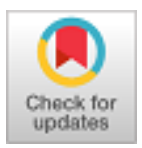

\begin{abstract}
The downstream scour of the control structure is a more common and very complex issue in river engineering. Flow structure in the vicinity of the control structure is entirely different from other parts of the river. Ansys Fluent Multiphase Eulerian model combined with hybrid Dense Discrete Phase Model (DDPM) provides much accurate and precise view of flow structure. This model provides a better understanding of flow structure, and it is associated scour development at upstream and downstream. Model simulation is performed on the trapezoidal weir and trapezoidal weir with sloping apron platforms to compare the flow structure, and it is associated scour. The erosion is computed by Mc Laury erosion model, and particle tracking is done using DDPM through a Lagrangian approach stimulate the movement of particles within the flow domain, velocity and other properties. This research focused on delivering much better anticipation about all flow features and sediment particle tracking captured in a closer manner. In this analysis with the trapezoidal weir, the velocity reached around $0.835 \mathrm{~ms}-1$. However, as in the case of trapezoidal weir with sloping apron, the maximum velocity goes approximately $0.505 \mathrm{~ms}-1$ which are nearly equal to inlet velocity. From the analysis, the sloping apron proves to be significant in protecting the downstream side of the control structure.
\end{abstract}

Keywords: CFD, Scour control, Sediment transport, Grade control structure

\section{INTRODUCTION}

From past years, river restoration has been emerged as a significant topic to improve Rivers Bathymetry. Rivers are highly turbulence, meander and braided in nature. The carrying capacity of the channel is influenced by the cross-sectional shape of the channel for braided rivers; the carrying capacity is reduced due to the formation of shoals which leads to flooding. To avoid this situation different river restoration practice being practiced, constructing grade control structure across the entire width of the river is one of such measures. Grade control structure like weir not only limited to maintain the cross-sectional shape of the channel but also provides head-water storage along with protecting the bank from erosion etc. The effect of jet overflow at

Revised Manuscript Received on October 30, 2019.

* Correspondence Author

R. Karthik*, Civil engineering department, National Institute of Tcehnology, Silchar, Assam, India.

U. Kumar, Civil engineering department, National Institute of Tcehnology, Silchar, Assam, India.

A. K. Barbhuiya, Civil engineering department, National Institute of Tcehnology, Silchar, Assam, India.

(C) The Authors. Published by Blue Eyes Intelligence Engineering and Sciences Publication (BEIESP). This is an open access article under the CC BY-NC-ND license (http://creativecommons.org/licenses/by-nc-nd/4.0/) downstream structure leads towards the development of the scour hole, due to the advancement of the scour hole which undermines the foundation of the structure and leads to its failure [1]. Since 1932, numerous research works have been carried out on the flow structure and scour hole formation at downstream of grade control structures. [1]-[5] and many more studied the flow and scour parameters experimentally and found expression to predict the scour profile like maximum length, depth of the scour hole and impacting features of scouring formation like tail-water depth, height of the structure and ratio of upstream and downstream water depth etc. [6] have studied the flow dynamics near the control structure numerically [7] have examined the bed particle deformation in front of the weir. Measures for protection against erosion are very costly as it requires, protection of the vast area of the bed. Moreover, it is experienced that some shear failure at the end of the bed protection and subsequent progressive scour process leads to the flop of the structure [8]. To overcome these issues and to design an effective control structure, designers need to have in-depth knowledge of the downstream flow structure, and associated scour parameters. However, some features of the flow and scour mechanisms either could not be mimicked in the laboratory or field study, moreover observation is very costly and time-consuming. Therefore, Computational Fluid Dynamics (CFD) is the tool which can easily be used to identify or to demonstrate these characteristics. In the recent years, a wide range of hydraulic parameters studied with CFD become much cost effective as reported by [9]. Development of Computing power and sophisticated CFD codes in past years played a vital role in the hydraulic and river engineering research [10]. Many researchers like [11]-[15] and others studied the flow and scour profile at downstream of grade control structure. Nowadays many commercial and open sources CFD software's are available, among one of them is Ansys Fluent software which is widely used to solve an industrial oriented problem because it offers a wide variety of simulation option with different numerical algorithms. K- $\varepsilon$ turbulence model together with VOF model is well capable of simulating the flow field over the weir in a rectangular channel [16]. [17] had studied sand particle erosion with multiphase flow condition by using supercomputer having 256 cores computational power with Ansys fluent VOF model for the run-time of $30 \mathrm{sec}$. Mc Laury erosion model is widely used in oil and gas field to study the erosion behavior of slurry flows at the surface of the pipe but has not been utilised by any other researchers to investigate the erosion behavior in river engineering.

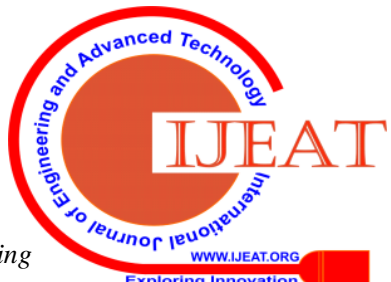


The primary objective of this article is to identify the cause and effects of scour hole in upstream and downstream of the trapezoidal weir and trapezoidal weir with the sloping apron. Based on our knowledge there is no such article focused on computational approach to study the flow, scour at downstream and particle tracking using Ansys Fluent in river engineering.

\section{MODEL DECRIPTION}

A. The simulation of flow features and other parameters in $3 \mathrm{D}$ is very costly because it requires high computing power and time consuming, the flow features are not varying much with respect to width of the channel, so the present study carried out with the 2D case. The 2D model of flow domain with the sand bed was created using Ansys Design modeller, which displayed in Fig.1, the total length of the flow domain was $8 \mathrm{~m}$, and depth of the flow domain was $1 \mathrm{~m}$ including 20 $\mathrm{cm}$ sand bed and $80 \mathrm{~cm}$ flow depth. A trapezoidal weir located at $3 \mathrm{~m}$ from inlet having base width $30 \mathrm{~cm}$, top breadth $10 \mathrm{~cm}$ and height $40 \mathrm{~cm}$ was considered. The downstream sloping apron that has $70 \mathrm{~cm}$ length, $30 \mathrm{~cm}$ depth $10 \mathrm{~cm}$ end sill and sloping bucket with a radius of $18 \mathrm{~cm}$ is chosen in the present model. The simulation of flow and erosion for trapezoidal weir is designated as 'case A' while the simulation for trapezoidal weir with sloping apron is designated as 'case B' for ease of understanding. In case A the trapezoidal structure starts and ends at $3 \mathrm{~m}$ and $3.3 \mathrm{~m}$ from inlet respectively. In the case of B the trapezoidal structure with sloping apron starts and ends at $3 \mathrm{~m}$ and $4 \mathrm{~m}$ form inlet respectively with the length of sloping apron being $0.7 \mathrm{~m}$. This study was mainly intended to study the flow features in the vicinity of the control structure. The location of weir from the inlet is sufficient enough to develop the turbulent flow, and downstream of the structure had an adequate length to visualize the flow features. Meshing is the process to discretize the entire domain into some smaller, non-overlapping sub-elements. Quality of solution and Stability of solution (convergence/divergence) strongly depends on the mesh quality. In the present study, meshing was done by Ansys meshing. Three different Quality of mesh-like coarse, medium and fine were carried out to ensure that the result is mesh independent [18]. The number of elements in the weir without apron model was 338,244 and weir with the sloping apron was 283,643. Five numbers of inflation layers were given all the boundary surfaces to well capture the property near wall surfaces. Mesh Quality like element quality, Skewness and orthogonal quality have been checked, and it has fulfilled the requirements as mentioned by [19].

\section{B. BMomentum Equation for DDPM}

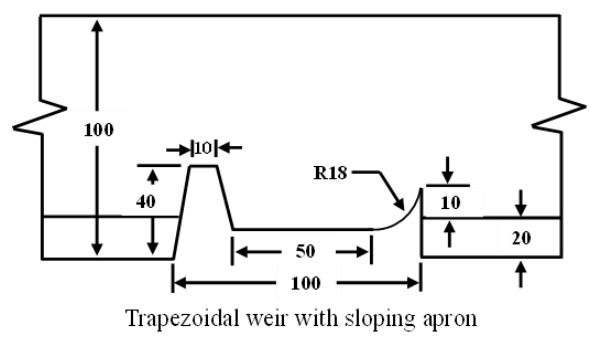

Retrieval Number F8285088619/2019@BEIESP

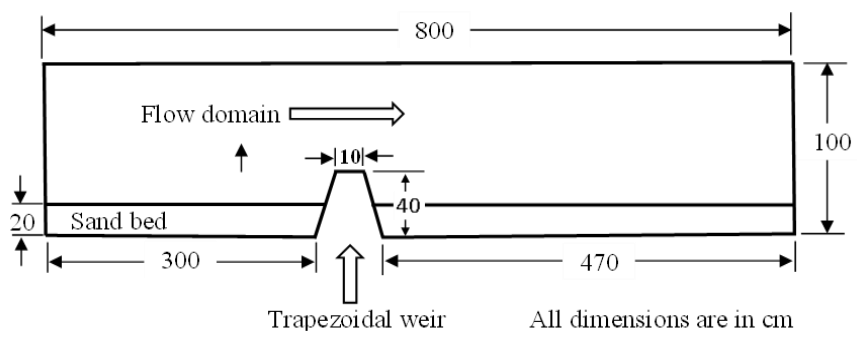

Fig. 1. Flow Domain And Sand Bed With Trapezoidal Weir With Sloping Apron At End

\section{NUMERICAL MODEL}

Among other CFD software's Ansys Fluent 18.0 software is sophisticated and offers many simulation options for different flow condition. The flow domain and sand bed involved in the present study, as a multiphase condition. The fluent software can effectively simulate the multiphase condition with Eulerian method. The fluent software could effectively track sand particle employing Discrete Phase Method (DPM) and Dense Discrete Phase Method (DDPM). The DPM can track only 10\% particle load, but DDPM can track more than $10 \%$ particle load from the total particles. This simulation with the support of Ansys Fluent multiphase model Eulerian with DDPM which is a hybrid model combines the Eulerian-Lagrangian approach; where the flow is simulated by Eulerian method and particle tracking is done by the Lagrangian method. Ansys Fluent software has several erosion models among Mc Laury erosion model can effectively simulate erosion behaviour of the slurry flows. So, Mc. Laury model was implemented in the present study

$$
\frac{\partial}{\partial_{\varepsilon}}\left(\alpha_{p} \rho_{p}\right)+\nabla \cdot\left(\alpha_{p} \rho_{p} \vec{v}_{p}\right)=\sum_{q=1}^{\text {nephases }}\left(\dot{m}_{q p}-\dot{m}_{p q}\right)
$$

to predict the erosion rate at downstream of the structure.

\section{Continuity Equation for DDPM (1)}

Where, $\vec{v}_{p}$ is the velocity of phase p, $\dot{m}_{q p}$ characterizes the mass transfer from the "q" phase to "p" phase, and $\dot{m}_{q p}$ characterizes the mass transfer from the " $p$ " phase to "q" phase. $\alpha_{p}$ and $\rho_{p}$ are the volume fraction and density of the phase $\mathrm{p}$ respectively. 


$$
\begin{gathered}
\frac{\partial}{\partial_{t}}\left(\alpha_{p} \rho_{p} \vec{v}_{p}\right)+\nabla \cdot\left(\alpha_{p} \rho_{p} \vec{v}_{p} \vec{v}_{p}\right)=-\alpha_{p} \nabla_{p}+\nabla \cdot\left[\alpha_{p} \mu_{p}\left(\nabla \vec{v}_{p}+\nabla \overrightarrow{v_{p}^{T}}\right)\right] \\
+\alpha_{p} \rho_{p} \vec{g}+F_{\text {vm,lift,user }}+\sum_{q=1}^{n p h a s e s}\left(\vec{K}_{q p}\left(\vec{v}_{q}-\vec{v}_{p}\right)+\dot{m}_{q p} \vec{v}_{q p}-\dot{m}_{q p} \vec{v}_{q p}\right) \\
+K_{D P M}\left(\vec{v}_{D P M}-\vec{v}_{p}\right)+S_{D P M, \operatorname{explicit}}
\end{gathered}
$$

Where, $\mu_{\mathrm{p}}$ is the shear viscosity of phase $\mathrm{p}, \mathrm{F}_{\mathrm{vm}}$, lift ,user is virtual mass force, lift force and user specified force. $S_{D P M}$, explicit and $\vec{v}_{D P M}$ are momentum exchange term for explicit and implicit. $\mathrm{K}_{\mathrm{DPM}}$ is particle averaged interphase momentum exchange coefficient.

\section{Realizable K- $\varepsilon$ Turbulence model}

And

$$
\frac{\partial}{\partial_{t}}(p k)+\frac{\partial}{\partial_{x j}}\left(\rho k u_{j}\right)=\frac{\partial}{\partial_{x j}}\left[\left(\mu+\frac{\mu_{t}}{\sigma_{k}}\right) \frac{\partial_{k}}{\partial_{x j}}\right]+G_{k}+G_{b}-\rho \varepsilon-Y_{m}+S_{k}
$$

$$
\frac{\partial}{\partial_{t}}(\rho \varepsilon)+\frac{\partial}{\partial_{x j}}\left(\rho \varepsilon u_{j}\right)=\frac{\partial}{\partial_{x j}}\left[\left(\mu+\frac{\mu_{t}}{\sigma_{\varepsilon}}\right) \frac{\partial_{\varepsilon}}{\partial_{x j}}\right]+\rho C_{1} S_{\varepsilon}-\rho C_{2} \frac{\varepsilon^{2}}{k+\sqrt{v \varepsilon}}+C_{1 \varepsilon} \frac{\varepsilon}{k} C_{3 \varepsilon} G_{b}+S_{\varepsilon}
$$

Where

$$
C_{1}=\max \left[0.43, \frac{\eta}{\eta+5}\right] \quad \eta=S \frac{k}{\varepsilon}, S=\sqrt{2 S_{i j} S_{i j}}
$$

initial (3) velocity is of $0.5 \mathrm{~ms}-1$, an outlet was pressure outlet, and the top portion of flow domain was kept as symmetry. For the $G_{k}$ is generation of turbulence kinetic energy due to mean velocity gradients; $G_{b}$ is generation of turbulence kinetic energy due to buoyancy. $C_{2}, C_{3 \varepsilon}$ and $C_{1 \varepsilon}$ are constants. $\sigma_{\mathrm{k}}$ and $\sigma_{\varepsilon}$ are the turbulent Prandtl numbers for $\mathrm{K}$ and $\varepsilon$ respectively. $\mathrm{S}_{\mathrm{k}}$ and $\mathrm{S}_{\varepsilon}$ are User-defined source term. $\mathrm{Y}_{\mathrm{m}}$ represents the contribution of the fluctuating dilation in compressible turbulence to the overall dissipation rate, $\mathrm{S}$ is the modulus of the mean rate-of-strain tensor.

\section{E. Mc Laury Erosion Model}

$$
\begin{gathered}
E=A V^{n} f(\gamma) \\
A=F B h^{k} \\
f(\gamma)=b \gamma^{2}+c \gamma
\end{gathered}
$$

Where $\mathrm{F}$ is empirical constant, $\mathrm{V}$ is particle impact velocity, $\mathrm{Bh}$ is brinell's hardness number of wall material, $\mathrm{K}$ is constant for material property, $\gamma$ is the particle impingement angle and b, c are the constant. The detailed description of all above mentioned equation is available in [20].

\section{BOUNDARY CONDITION}

This simulation was conducted by using the Intel Core i7 machine with four parallel processing. In zone condition, the primary phase was selected as water and secondary phase was selected as sand. Inlet chosen as a velocity inlet with given velocity the Reynolds number $(\mathrm{Re})$ and Froude number (F) is 723553 and 0.17 respectively. The sand particle is considered as an inert particle, and particle injection was selected as a surface injection, sand particle initial velocity was set as zero. Particle distribution is not linear, fluent offers Rosin-Rammler equation to fit the particle size distribution with a different mass fraction by putting minimum, maximum and mean size of the particles. Two-way turbulence coupling is enabled to consider the effect created by the particle in the flow domain and vice-versa. The under-relaxation factor URF from solution control was given as 0.3 and 0.7 for momentum and pressure to ensure solution stabilization. A time step size was $0.01 \mathrm{sec}$, the total number of time step was 5000, and per time step 20 numbers of iteration was given, totally one lakh numbers of iteration was given, and it took nearly 72 hours to complete the simulation for the run time of $50 \mathrm{sec}$. The particle injection was started at $3 \mathrm{sec}$, because the flow was well developed and capable of carrying those particles at this stage and every $0.01 \mathrm{sec}$ of time step particles was released from the top surface of the sand bed, and finally particles injection was stopped at $5 \mathrm{sec}$ due to the limitation of computing power.

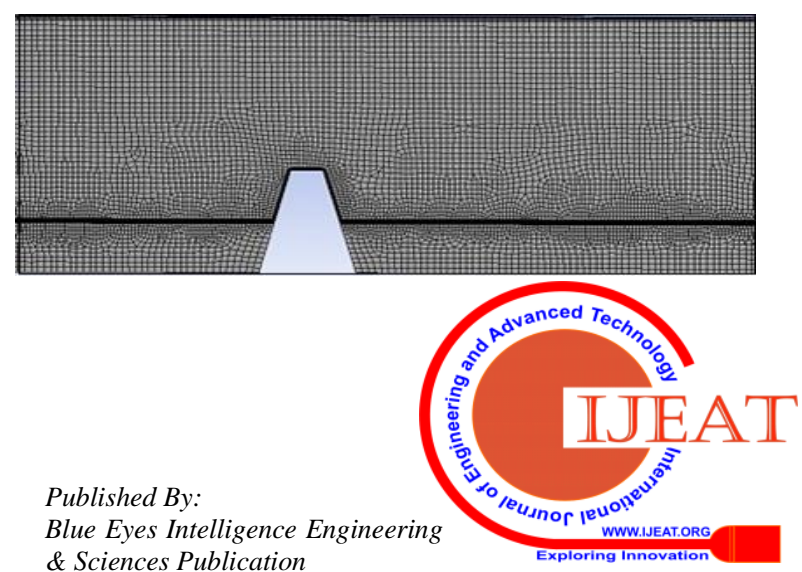




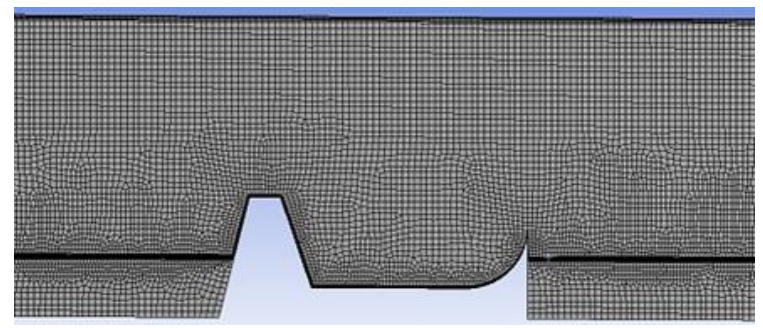

Fig. 2. Closer View Of Mesh At Trapezoidal Weir And Weir With Sloping Apron.

Table- I: Particle Description

\begin{tabular}{|l|l|}
\hline Density & $1850 \mathrm{~kg} \mathrm{~m}-3$ \\
\hline Particle Distribution & Rosin-Rammler \\
\hline Starting time of particle injection & $3 \mathrm{sec}$ \\
\hline Finishing time of particle injection & $5 \mathrm{sec}$ \\
\hline Minimum Diameter & $0.00005 \mathrm{~m}$ \\
\hline Maximum Diameter & $0.00236 \mathrm{~m}$ \\
\hline
\end{tabular}

Table- II: Numerical scheme and solution methods

\begin{tabular}{|l|l|l|}
\hline $\begin{array}{l}\text { SI } \\
\text { no }\end{array}$ & Variable & Setting \\
\hline 1 & Turbulence model & Realizable-k- $\varepsilon$ \\
\hline 2 & Pressure velocity coupling & Phase coupled SIMPLE \\
\hline 3 & Gradient & Green-Gauss node based \\
\hline 4 & Momentum & Second order \\
\hline 5 & Volume fraction & QUICK \\
\hline 6 & Turbulence Kinetic Energy & Second order \\
\hline 7 & Turbulence Dissipation rate & Second order \\
\hline 8 & Transient Formulation & Second order implicit \\
\hline 9 & Initialization & Hybrid initialization \\
\hline 10 & Time step & 0.01 sec \\
\hline 11 & Maximum iteration per time step & 20 \\
\hline
\end{tabular}

\section{RESULT AND DISCUSSION}

The velocity is considered as a crucial parameter in the flow as well as erosion behavior at downstream of the control structure as the erosion is directly proportional to the magnitude of the velocity. Figure 3 shows the velocity contour of the flow domain at the trapezoidal weir and trapezoidal weir with the sloping apron. Form the figure it is observed that the velocity at downstream of the trapezoidal weir is quite higher than the trapezoidal weir with the sloping apron. Maximum velocity at trapezoidal weir is $0.835 \mathrm{~ms}-1$, and trapezoidal weir with sloping apron is $0.505 \mathrm{~ms}-1$. In case $A$ and $B$, just upstream at the bottom of the structure the velocity is very less due to the sudden obstruction which is indicated in blue colour. In case A at the bed of downstream side the high-velocity magnitude (yellow colour) surrounded by low-velocity magnitude (blue colour) indicates the flow separation. But in case B just above the apron high-velocity magnitude surrounded by a low magnitude of velocity which leads the flow separation.

Figure 4 shows the longitudinal velocity distribution of the flow domain for both cases. In the case of A, observed negative velocity found at the downstream side of the structure which looks in blue indicates that development of vortex flow and flows towards the opposite direction of mean flows. In case $\mathrm{B}$ also found the same vortex flow above the apron. Distribution of vertical velocity for case A and case B are shown in figure 5 The maximum velocity is observed at the crest of the control structure in both cases though the magnitude is higher in case $B$. In case $B$, the vertical velocity is less at the downstream side when compared to the upstream side of the structure but in case A at $7 \mathrm{~m}$ from inlet there are small changes in the magnitude other than that minor variation in vertical velocity throughout the domain.

Figure.6 Depicts that the velocity vectors of flow domain at trapezoidal weir and weir with a sloping apron. In both cases, vector magnitude and colour indicate that velocity is high at upstream and above the structure but once the flow crossed the structure the velocity is reduced drastically. A secondary Swirl flow zone is developed at the bottom of the jet flow which leads to the flow separation. This pattern can be observed through vector plot at the downstream side of the structure in case A, and above the apron in case B. Similar flow features were reported by previous researchers [21].

Stream-lines provide a better understanding to visualize how the flow passes over the control structures. Figure.7 and 8 shows the stream-lines or path lines of the flow domain for both cases. There is a small eddy flow generated on the upstream side of the control structure due to the back-flow of the obstruction which can be seen through fig. 8. In both cases, a strong Secondary Circular Flow Zone (SCFZ) is generated at the downstream side of the weir. The magnitude of secondary circular flow zone playing a vital role in the development of the scour hole, as per the observation of [22]. Due to the SCFZ, the flow separation occurred at the downstream side of the weir but at downstream end of the SCFZ the flow started to re-attach with the main flow which is called point of re-attachment [8] which is clearly shown in figure 8 in a closer view. In case B two secondary circular flow zones are formed on the downstream of the weir. Among the two SCFZ, one is close to the bed of the apron which is marked as 1 and another one is above the SCFZ1 which marked as 2. The SCFZ 2 is stronger in nature and SCFZ 1 is weaker. This kind of formation of two secondary circular flow zones is unique and is not observed in case A which needs to be explored further. Majority of the erosion causing secondary vortices are lies above the apron structure in case B but in case A the erosion causing SCFZ are formed at bed surfaces of the downstream side with high magnitude. Again, in case B one more SCFZ are formed at sill end of the sloping bucket of apron which may lead erosion at downstream of weir, but the magnitude of SCFZ is much less when compared to case A. In both condition, the flow starts to regain its original properties and become strong after the point of reattachment. In case A one more circular flow zone is again formed at around $7 \mathrm{~m}$ from the inlet which is very strong and at near the bed. 


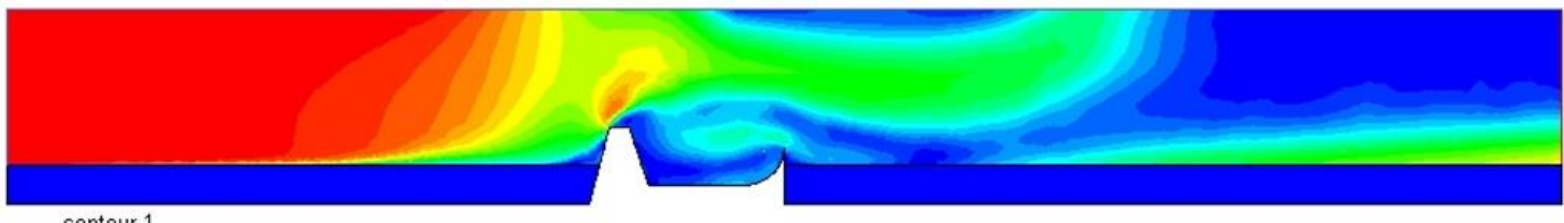

contour-1

Velocity Magnitude (flow-domain)

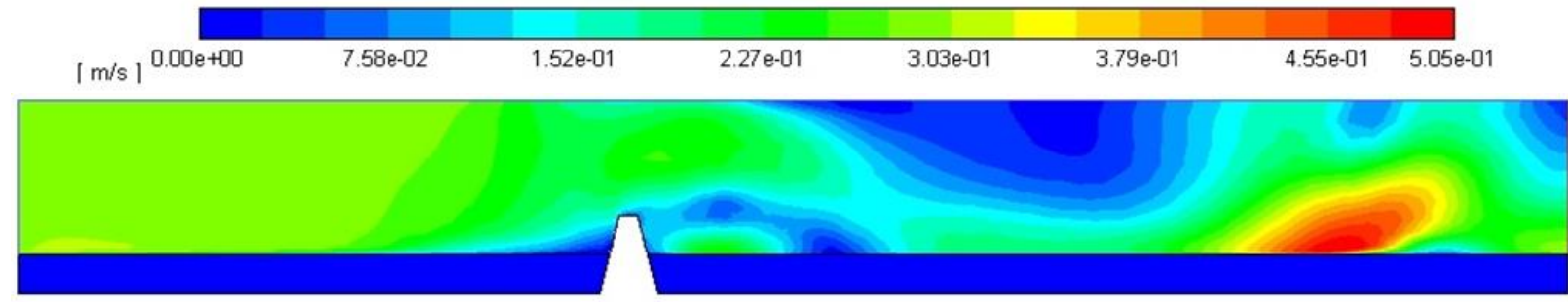

contour-1

Velocity Magnitude (flow-domain)

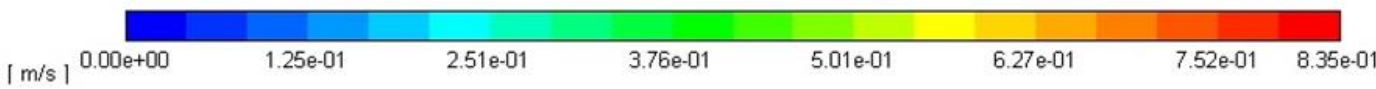

Fig. 3. Contour Of The Mean Velocity Of The Flow Domain At Trapezoidal Weir And Weir With The Sloping Apron

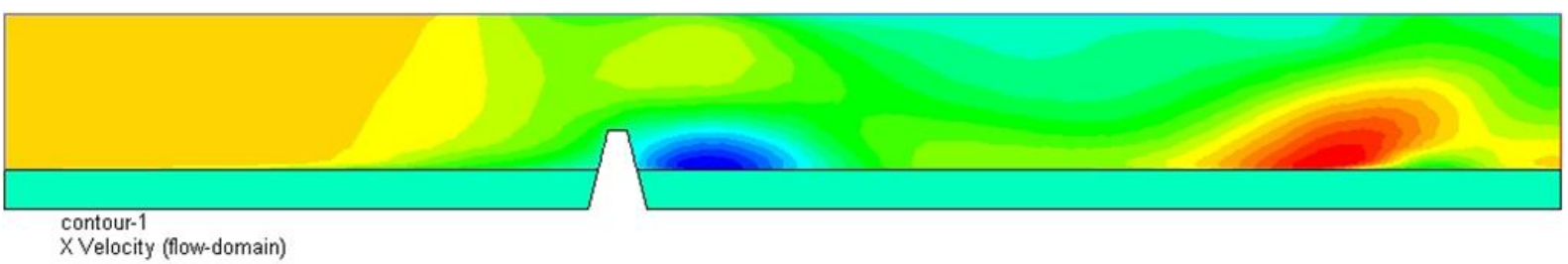

\begin{tabular}{|c|c|c|c|c|c|c|}
\hline$[\mathrm{m} / \mathrm{s}]^{-4.08 \mathrm{e}-01}$ & $-2.22 \mathrm{e}-01$ & $-3.51 \mathrm{e}-02$ & $1.51 \mathrm{e}-01$ & $3.38 \mathrm{e}-01$ & $5.24 \mathrm{e}-01$ & 7.11e-01 \\
\hline
\end{tabular}

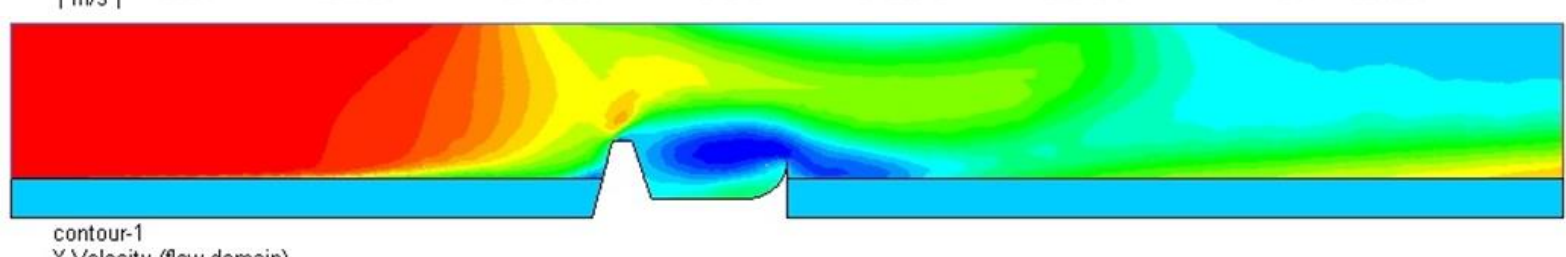

$X$ Velocity (flow-domain)

\begin{tabular}{llllllll}
\hline $\mathrm{m} /\left.\mathrm{s}\right|^{-1.63 e-01}$ & $-6.26 \mathrm{e}-02$ & $3.76 \mathrm{e}-02$ & $1.38 \mathrm{e}-01$ & $2.38 \mathrm{e}-01$ & $3.38 \mathrm{e}-01$ & $4.38 \mathrm{e}-01$ & $5.05 \mathrm{e}-01$
\end{tabular}

Fig. 4. Contour Of Longitudinal Velocity Of Flow Domain At Trapezoidal Weir And Weir With A Sloping Apron

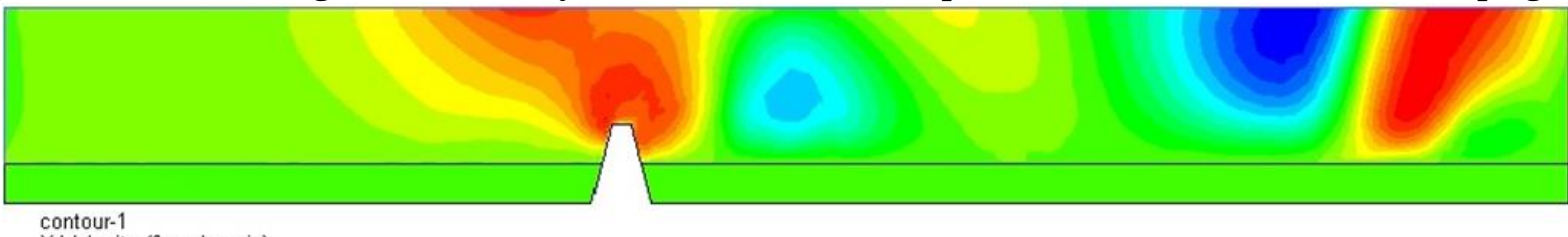

Y Velocity (flow-domain)

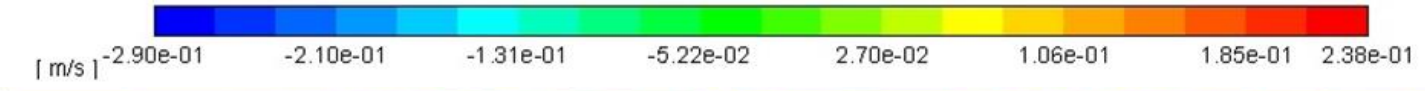

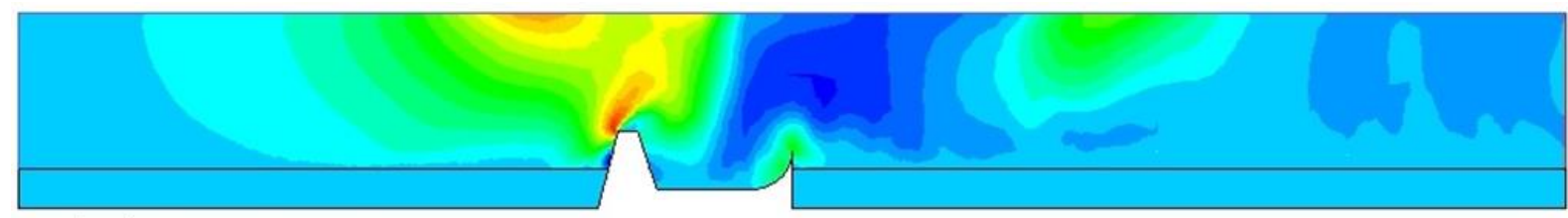

contour-1

$Y$ Velocity (flow-domain)

$\mid$\begin{tabular}{llllllll}
\hline $\mathrm{m} /\left.\mathrm{s}\right|^{-9.51 \mathrm{e}-02}$ & $-3.45 \mathrm{e}-02$ & $2.62 \mathrm{e}-02$ & $8.68 \mathrm{e}-02$ & $1.48 \mathrm{e}-01$ & $2.08 \mathrm{e}-01$ & $2.69 \mathrm{e}-01$ & $3.09 \mathrm{e}-01$
\end{tabular}

Fig. 5. Contour of the vertical velocity of the flow domain at trapezoidal weir and weir with sloping 
Two-Dimensional analysis of flow field and associated scour parameters at downstream of weir with and without sloping apron

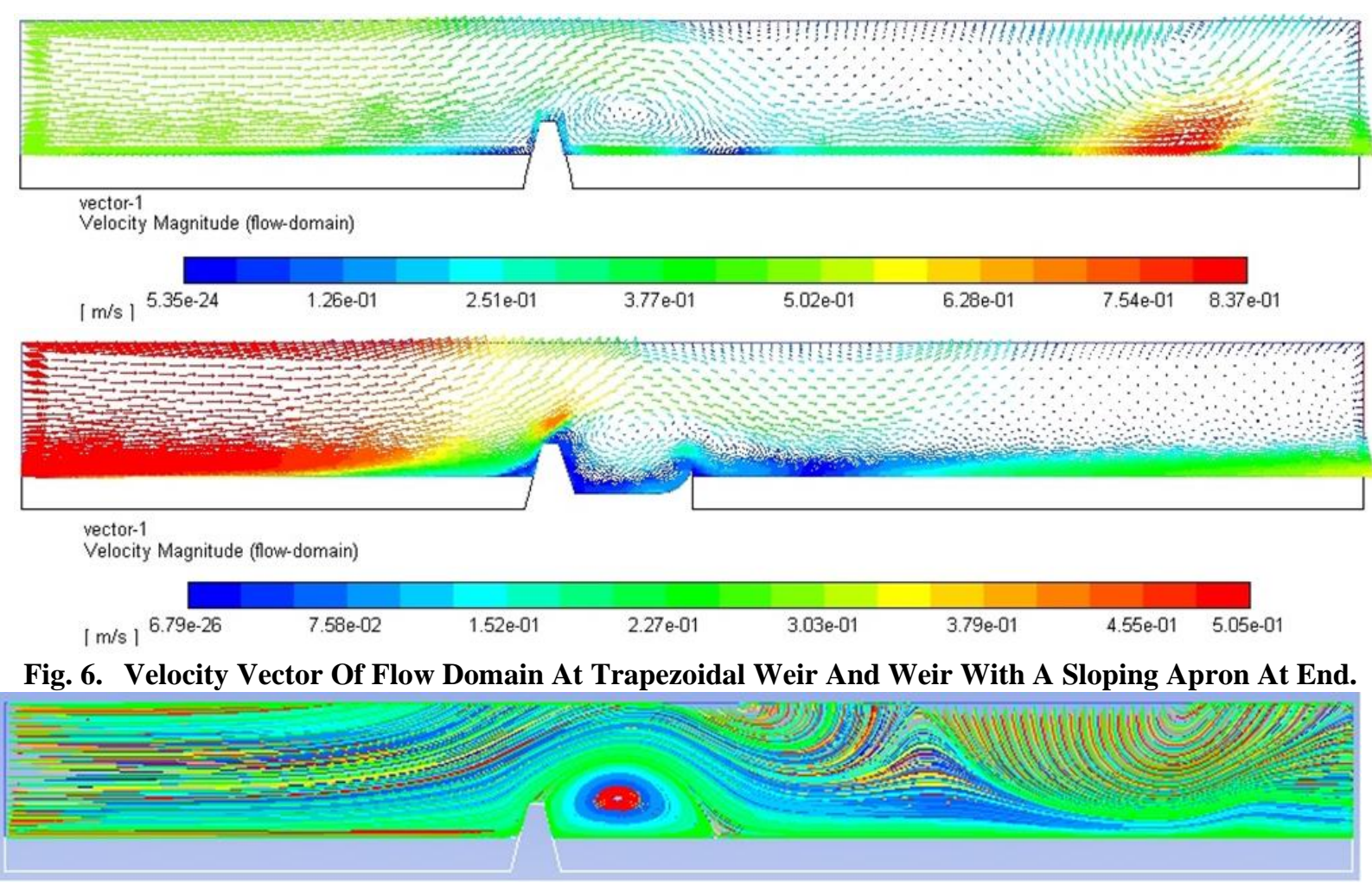

Fig. 7. Stream-Lines Of Flow Domain At Trapezoidal.

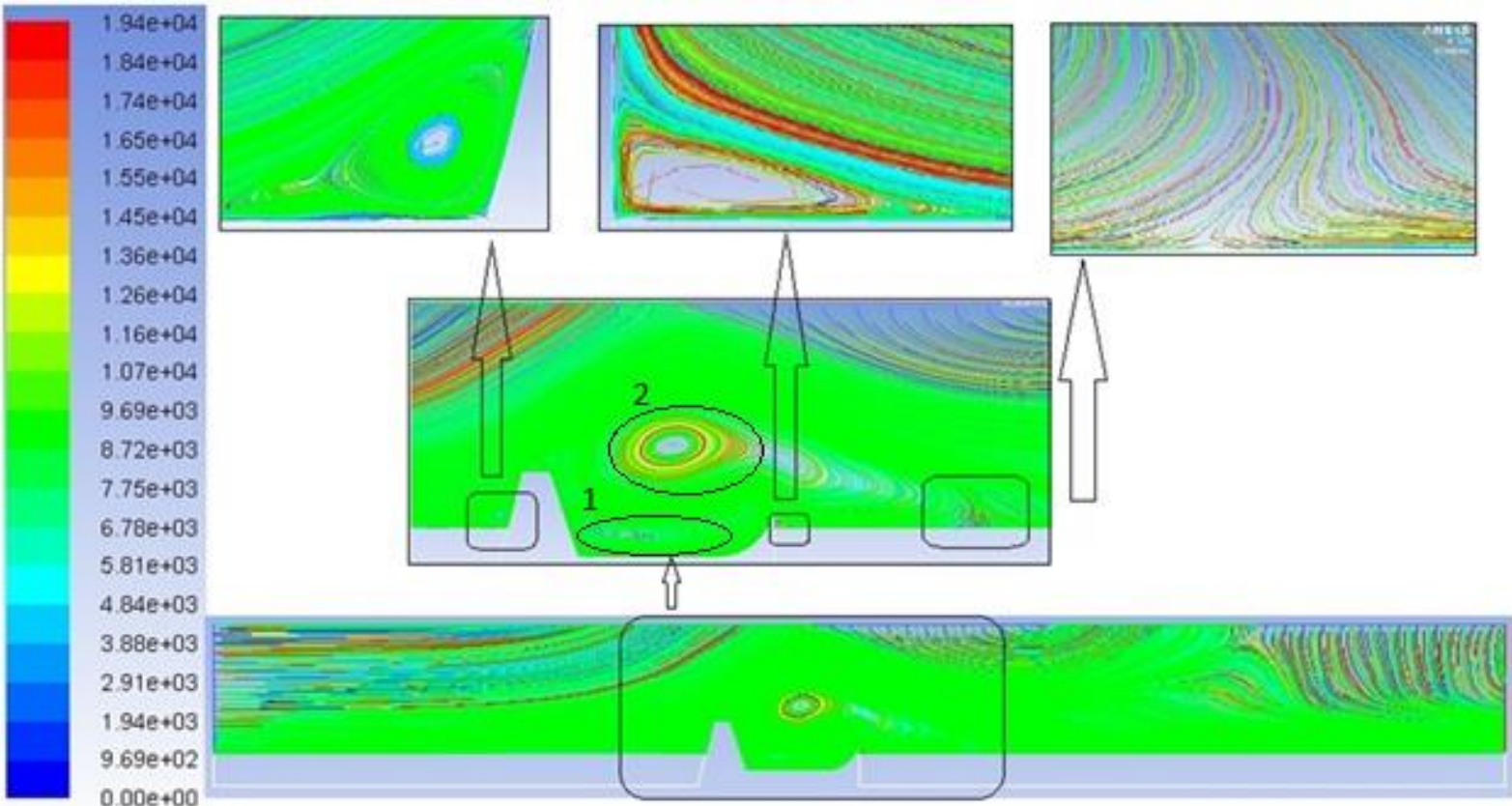

Fig. 8. Stream-Lines Of Flow Domain At Trapezoidal Weir Cum Sloping Apron At End.

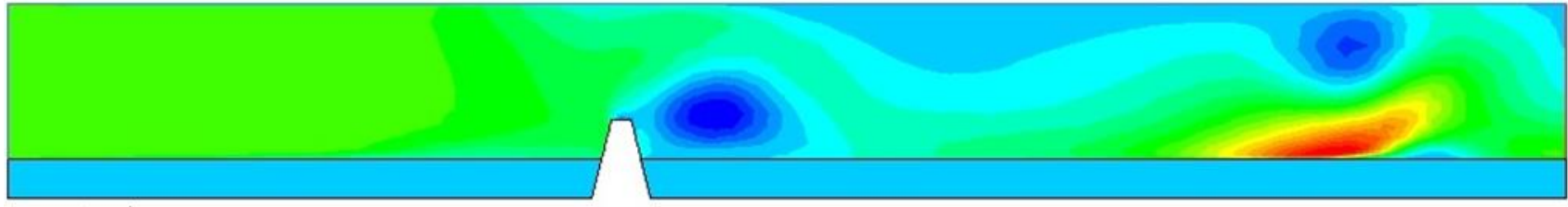

contour-1

Total Pressure (flow-domain)

\begin{tabular}{|c|c|c|c|c|c|c|c|}
\hline [ pascal $9.02 e+01$ & $-2.85 e+01$ & $3.32 \mathrm{e}+01$ & $9.49 e+01$ & $1.57 e+02$ & $2.18 \mathrm{e}+02$ & $2.80 e+02$ & $3.21 e+02$ \\
\hline
\end{tabular}

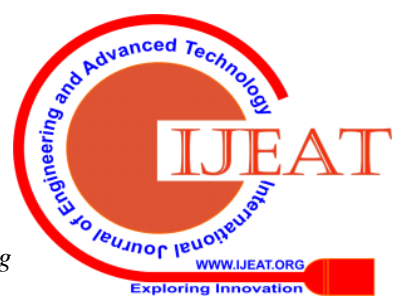




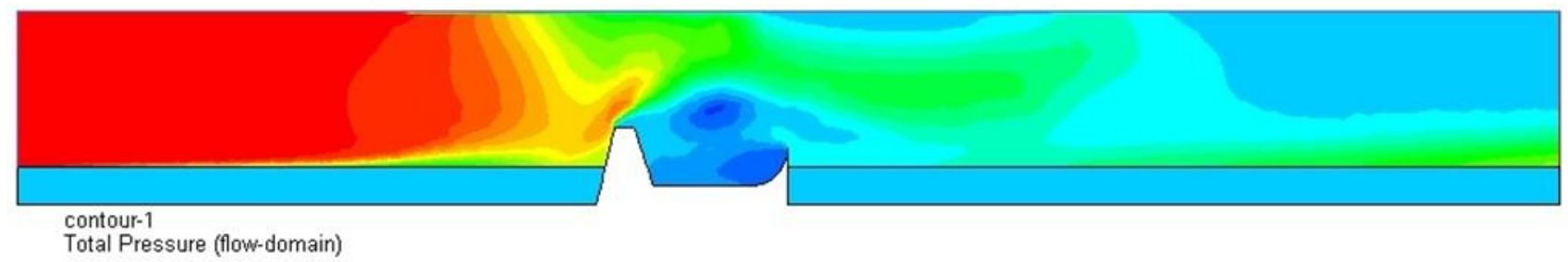

$\begin{array}{llllllll}\text { I pascail } 3.83 e+01 & -1.29 e+01 & 1.25 e+01 & 3.78 e+01 & 6.32 e+01 & 8.86 e+01 & 1.14 e+02 & 1.31 e+02\end{array}$

Fig. 9. Contour Of Total Pressure Of Flow Domain At Trapezoidal Weir And Weir With The Sloping Apron.

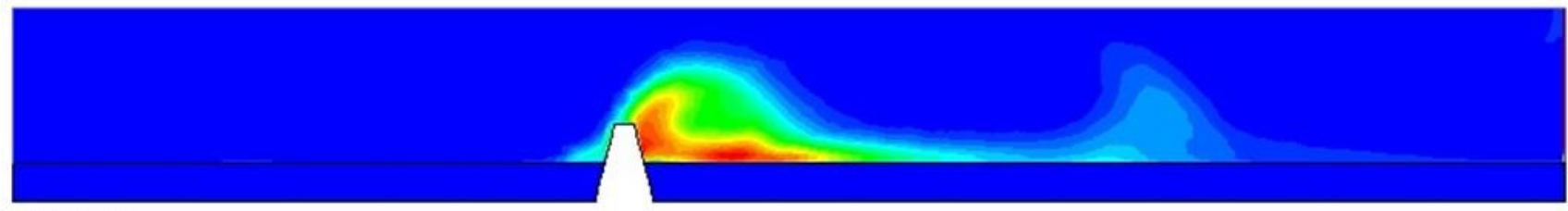

contour-2

Turbulent Kinetic Energy ( $k$ ) (flow-domain)

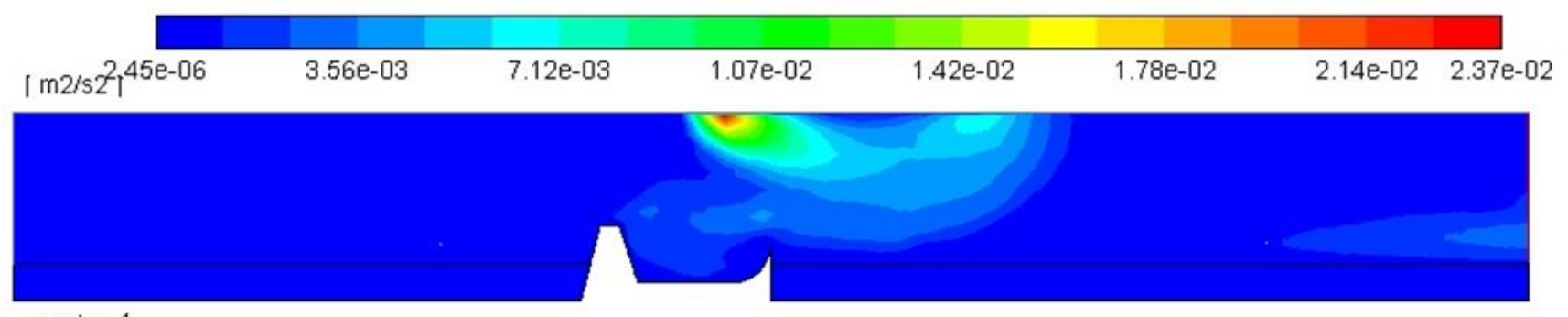

contour-1

Turbulent Kinetic Energy (k) (flow-domain)

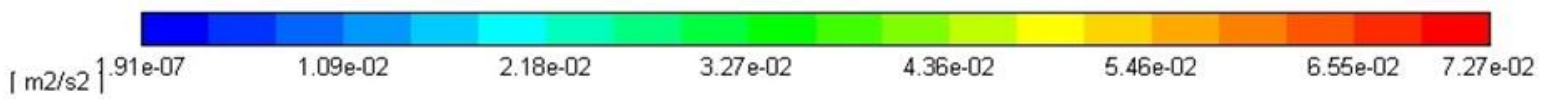

Fig. 10. Contour Of Turbulent Kinetic Energy Of Flow Domain At The Trapezoidal Weir And Trapezoidal Weir With The Sloping Apron.

The total pressure variation of flow domain for both case A and $\mathrm{B}$ is illustrated in figure 9 The maximum pressure for Case $\mathrm{A}$ is $3.21 \mathrm{e}+02 \mathrm{~Pa}$ and that of case $\mathrm{B}$ is $1.31 \mathrm{e}+02 \mathrm{~Pa}$. The pressure at the upstream side of the control structure is higher than the downstream side of the control structure. In both case $\mathrm{A}$ and $\mathrm{B}$, the pressure value plunge to negative at the secondary circular flow zone formed near the downstream side of the control structure. In case A, pressure value at the downstream side is $-9.02 \mathrm{e}+01 \mathrm{~Pa}$, and in the case of $\mathrm{B}$, it is $-3.83 \mathrm{e}+01 \mathrm{~Pa}$. it is observed that maximum pressure in case $\mathrm{A}$ is higher than case $\mathrm{B}$.

Generally, above the crest and at the downstream of the control structure the flow is highly turbulent. Figure 10 shows the characteristics of the turbulent kinetic energy of flow domain with trapezoidal weir and trapezoidal weir with a sloping apron. In case A, the maximum value of turbulent kinetic energy is 2.31e-02 Occurring near the bed on downstream of control structure and in case B, it is 6.55e-02 located above the sloping apron near the free surface of the flow. Turbulent viscosity, turbulent viscosity ratio and Reynolds number of flow domain follow a similar trend for both case.

Particle velocity at $50 \mathrm{sec}$ is depicted in figure 11 and 12 for case $A$ and case $B$ respectively. The minimum particle velocity in case A is 1.26 e- 03 ms- 1 with the majority of the particle velocity lying in the range of 3.59 e-01 to 3.99 e-01 ms-1, very few particles gained higher velocity. Similarly, the minimum velocity for case $B$ is 2.78 e- 05 ms- 1 with the majority of the particle velocity lying in the range of 3.2e-01 to $3.55 \mathrm{e}-01 \mathrm{~ms}-1$. The velocity of particle impingement is another important parameter which causes erosion. In case A the particles directly hit the bed surface and their velocity is very high at the bed surface which leads to scour formation at downstream of the structure. While in the case of B most of the particles are in suspension and particle velocity at bed surface is very less compared to case A 


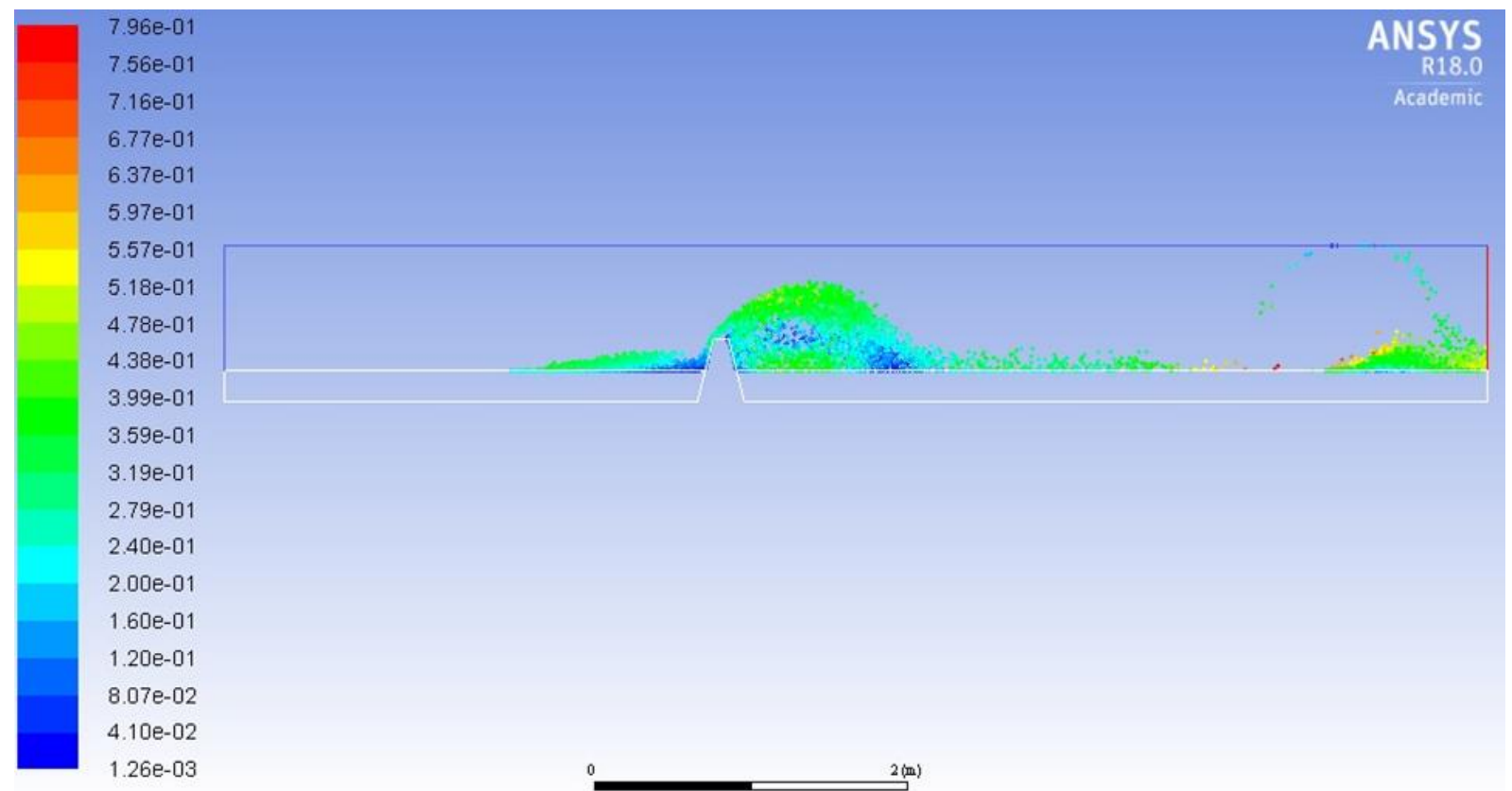

Fig. 11. Contour Of Particle Velocity Of The Flow Domain At The Trapezoidal Weir.

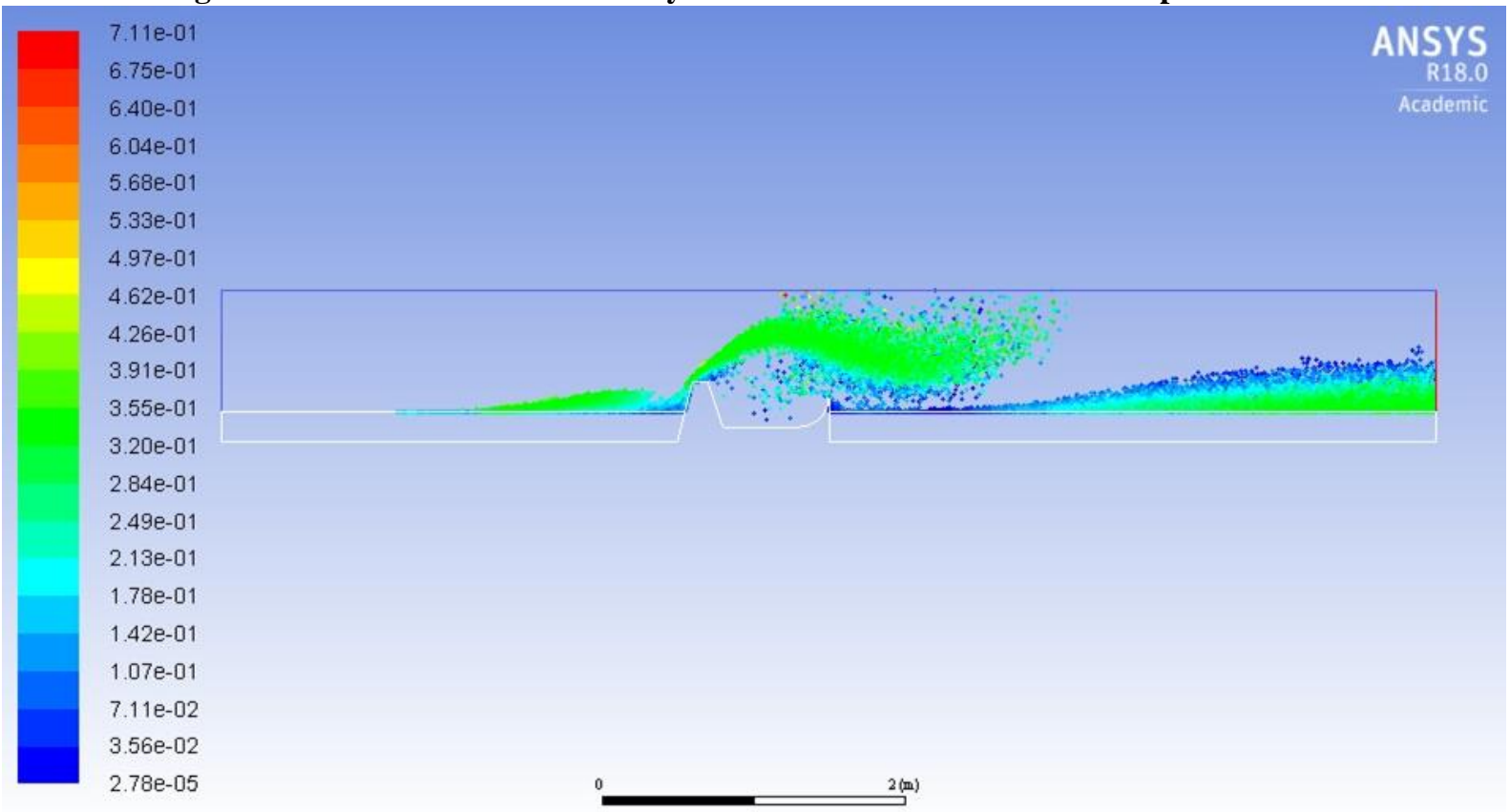

Fig. 12. Contour Of Particle Velocity Of Flow Domain At Trapezoidal Weir With A Sloping Apron

Figure 13 shows the velocity of the flow domain of trapezoidal weir and the trapezoidal weir with the sloping apron. In both cases, the initial inflow velocity is $0.5 \mathrm{~ms}-1$. In the upstream region of case $\mathrm{A}$, the flow velocity reduces from $0.5 \mathrm{~ms}-1$ at the inlet to $0.39 \mathrm{~ms}-1$ near the control structure. The flow velocity increases just above the crest of the structure and reduces once it crosses the structure with a maximum velocity of $0.85 \mathrm{~ms}-1$ observed at $7 \mathrm{~m}$ from the inlet. In the upstream region of case $B$, the flow velocity reduces from $0.5 \mathrm{~ms}-1$ at an inlet to 0.325 ms- 1 near the control structure. Just above the crest of the structure, velocity increases with a narrow peak region and further decreases at the downstream of the structure. The maximum velocity in case $B$ is the inlet velocity and spans up to $2 \mathrm{~m}$ from the inlet. In the case of $A$, the maximum velocity is higher than the inlet velocity, and in the case of $\mathrm{B}$, the maximum velocity is almost equal to inlet velocity. The final comparison of both arguments shows that the use of trapezoidal weir with sloping apron in case $B$ reduces the flow velocity in the downstream region which ultimately reduces the scour formation. Shear stress distribution at the sand bed is shown in figure 14 for both cases. In both cases, a small peak in shear stress is observed at around $2.5 \mathrm{~m}$ from the inlet due to secondary circular flow formation. In case B it is visible and in case $\mathrm{A}$ it is not visible due to the band of scale. In the case of $\mathrm{A}$, the maximum shear stress reaches nearly $1.01 \mathrm{e}+00$, and in the case of $\mathrm{B}$, it is around $1.30 \mathrm{e}-01$. Figure 15 shows the erosion rate for $50 \mathrm{sec}$ of Mc. Laury model for trapezoidal weir and trapezoidal weir with a sloping apron. The erosion starts from the inlet and at $0.5 \mathrm{~m}$ there is a small change in the erosion rate, and one more peak is also observed at the upstream side of the control structure.

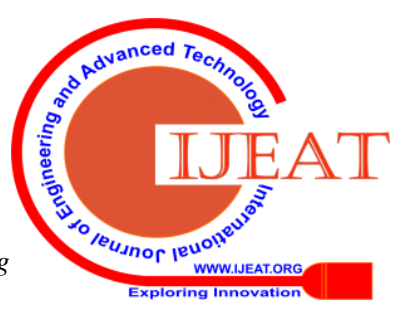


The erosion rate and its behaviour are quite similar in the upstream side of the structure for both cases. In case A the downstream erosion rate is nearly $1.00 \mathrm{e}-08 \mathrm{~kg} \mathrm{~m}-2$ which is higher than upstream side erosion rate. At $4.3 \mathrm{~m}$ from an inlet, the erosion rate is very less which indicates that there is a deposition at the end of the secondary circular flow zone. Beyond $4.3 \mathrm{~m}$ the erosion rate is increasing, and it reaches the maximum value at the outlet which is equal to $1.80 \mathrm{e}-08 \mathrm{~kg}$ $\mathrm{m}-2$. In case $B$, much less erosion rate is observed close to the structure in the downstream region as compared to the upstream region and followed by deposition at the end of the small secondary circular flow zone. Again, the erosion rate increases further until it reaches the outlet where the maximum erosion rate is $1.20 \mathrm{e}-08 \mathrm{~kg} \mathrm{~m}-2$ which is less than case A.
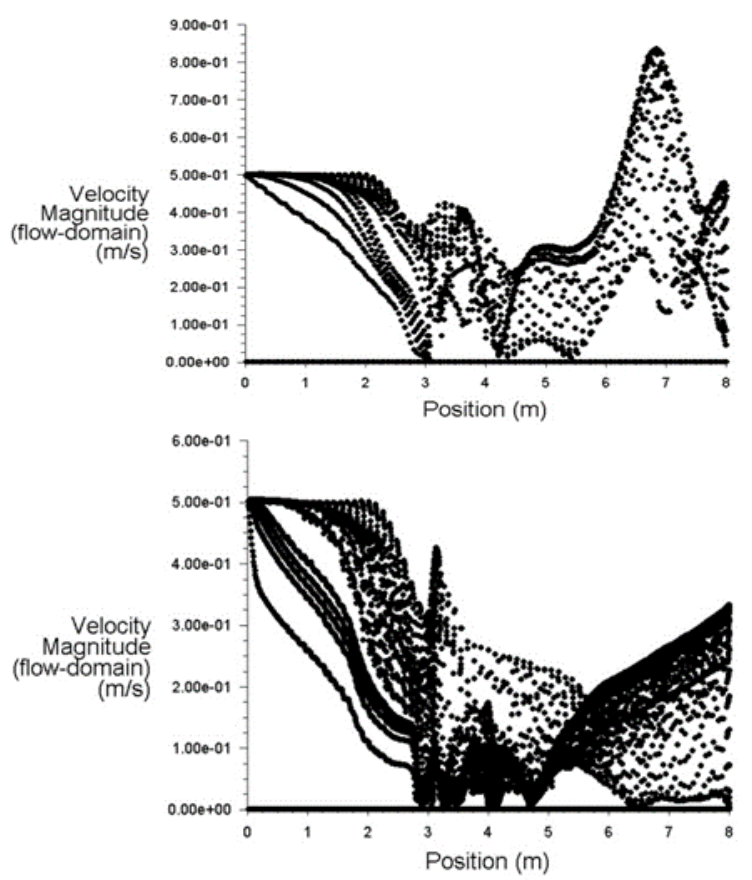

Fig. 13. Velocity Magnitude At Trapezoidal Weir (Top) And Trapezoidal Weir With Sloping Apron (Bottom).
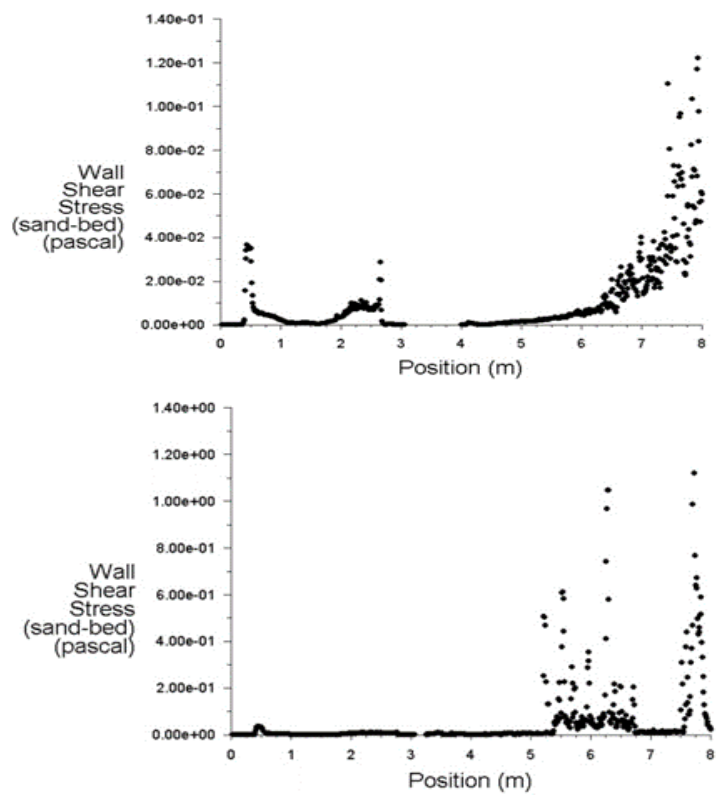

Fig. 14. Shear stress at trapezoidal weir (Top) and trapezoidal weir with sloping apron (Bottom).
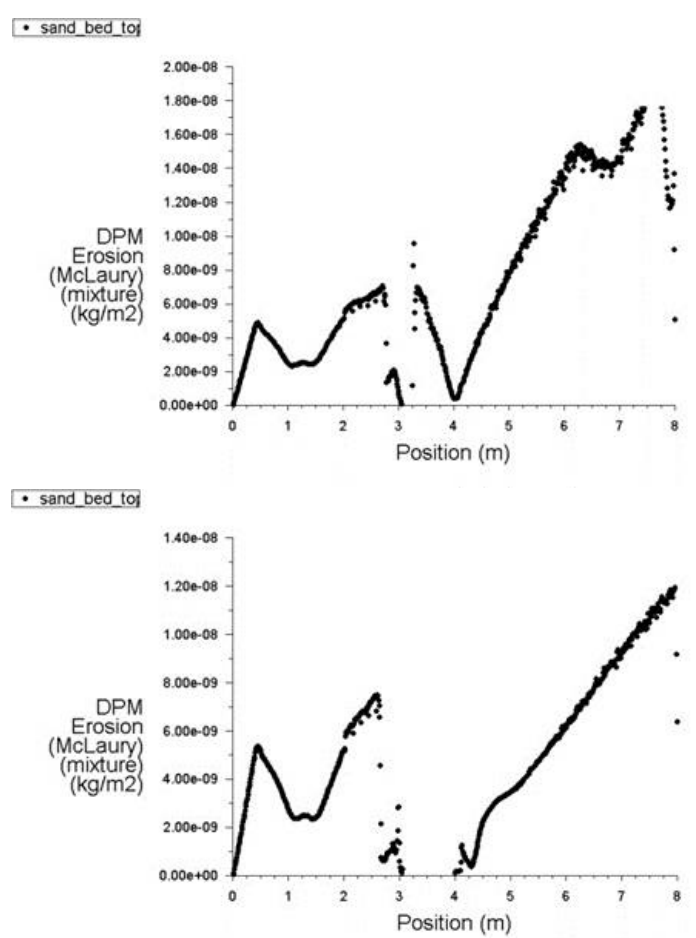

Fig. 15. Erosion Rate At Trapezoidal Weir (Bottom) And Trapezoidal Weir With Sloping Apron (Top).

\section{CONCLUSION}

This research is mainly intended to study the flow features, and their associated scour at the downstream of control structure and to reduce the scour at the downstream side which could lead towards the failure of the entire structure. In the present study, the presence of secondary circular flow zone at both upstream and downstream sides of the control structure can be successfully depicted. In case B, two secondary circular flow zones are generated above the apron; this is unique and needs to be explored further. DDPM model gives the provision of visualizing the particle tracking with different parameters like particle residence time, particle velocity in the longitudinal and vertical direction, particle swirl velocity, particle diameter, particle Reynolds number and many other properties. The downstream velocity is much less in case $\mathrm{B}$ compared to case $\mathrm{A}$, and the magnitude of scour at the downstream of the trapezoidal weir is higher than that of the trapezoidal weir with a sloping apron. The high level of turbulence formed near the surface in case B aids in capturing more dissolved oxygen into the water from the atmosphere which is helpful for aquatic life. Hence this type of weir with sloping apron proved to be a better engineering solution towards better life expectancy. 


\section{REFERENCES}

1. N. E. Bormann and P. Y. Julien (1991) "Scour downstream of grade-control structures." Journal of Hydraulic Engineering117, no. 5: 579-594. https://doi.org/10.1061/(ASCE)0733-9429(1991)117:5(579)

2. N. Rajaratnam and A. Benjamin (1983) "Flow near groin-like structures." Journal of Hydraulic Engineering109, no. 3: 463-480. https://doi.org/10.1061/(ASCE)0733-9429(1983)109:3(463)

3. V. D'Agostino and V. Ferro. (2004) "Scour on alluvial bed downstream of grade-control structures." Journal of Hydraulic Engineering 130, no. 1 1: 24-37. https://doi.org/10.1061/(ASCE)0733-9429(2004)130:1(24)

4. S. Dey and S. Arindam (2006) "Scour downstream of an apron due to submerged horizontal jets." Journal of hydraulic engineering 132, no. 3: https://doi.org/10.1061/(ASCE)0733-9429(2006)132:3(246)

246-257.

5. S. Pagliara, M. Palermo, S. M. Kurdistani, and L. S. Hassanabadi. (2015) "Erosive and hydrodynamic processes downstream of low-head control structures." Journal of Applied Water Engineering and $\begin{array}{llll}\text { Research } 3, & \text { no. } & \text { 2: } & \text { 122-131. }\end{array}$ https://doi.org/10.1080/23249676.2014.1001880

6. S. Kang and F. Sotiropoulos. "Numerical study of flow dynamics around a stream restoration structure in a meandering channel." Journal of Hydraulic Research 53, no. 2 (2015): 178-185. https://doi.org/10.1080/00221686.2015.1023855

7. S. Muller, P. Guiraud, and A. Line. (2011)"Particle bed deformation in front of a weir induced by subcritical laminar flow." Journal of Hydraulic Research 49, no. 2: 194-204. https://doi.org/10.1080/00221686.2011.552460

8. G.J.C.M. Hoffmans, and K. W. Pilarczyk. (1995) "Local scour downstream of hydraulic structures." Journal of Hydraulic Engineering 121, no. $\quad 4:$ 326-340. https://doi.org/10.1061/(ASCE)0733-9429(1995)121:4(326)

9. X. Lv, Q. Zou, and D. Reeve. (2011) "Numerical simulation of overflow at vertical weirs using a hybrid level set/VOF method." Advances in water resources 34, no. 10: 1320-1334. https://doi.org/10.1016/j.advwatres.2011.06.009

10. V. T. Nguyen and F. Nestmann. (2004) "Applications of CFD in hydraulics and river engineering." International Journal of Computational Fluid Dynamics 18, no. 2: 165-174. https://doi.org/10.1080/10618560310001634186।

11. T. Tingsanchali, and S. Maheswaran. (1990) "2-D depth-averaged flow computation near groyne." Journal of Hydraulic Engineering 116, no. 1: 71-86. https://doi.org/10.1061/(ASCE)0733-9429(1990)116:1(71)

12. S. K. Sinha and F. Marelius. (2000) "Analysis of flow past submerged vanes." Journal of Hydraulic Research 38, no. 1: 65-71. https://doi.org/10.1080/00221680009498360

13. K. Weidner, J. Petrie, P. Diplas, S. Nam, M. Gutierrez, and M. Ellenberg. "Numerical simulation of jet test and associated soil erosion." ICSE6 Paris(2012): 609-616.

14. M. Oertel, J. Balmes, and D. B. Bung. "Numerical simulation of erosion processes on crossbar block ramps." E-proceedings of the 36th IAHR World Congress 28 June - 3 July, 2015, The Hague, the Netherlands.

15. V. T. Nguyen, C. S. Moreno and S. Lyu. (2015) "Numerical simulation of sediment transport and bedmorphology around Gangjeong Weir on Nakdong River." KSCE Journal of Civil Engineering 19, no. 7: 2291-2297.

16. J. Qu, A. S. Ramamurthy, R. Tadayon, and Z. Chen. (2009) "Numerical simulation of sharp-crested weir flows." Canadian Journal of Civil Engineering 36, no. 9: 1530-1534. https://doi.org/10.1139/L09-067

17. M. Parsi et al. (2014) "A comprehensive review of solid particle erosion modeling for oil and gas wells and pipelines applications." Journal of Natural Gas Science and Engineering 21: 850-873. https://doi.org/10.1016/j.jngse.2014.10.001

18. M. S. Akoz, V. Gumus, and M. S. Kirkgoz. (2014) "Numerical simulation of flow over a semicylinder weir." Journal of Irrigation and Drainage Engineering 140, no. 6: 04014016 https://doi.org/10.1061/(ASCE)IR.1943-4774.0000717

19. M. M. Noor, A. P. Wandel, and T. Yusaf. (2013)"Detail guide for CFD on the simulation of biogas combustion in bluff-body mild burner." In Proceedings of the 2nd International Conference of Mechanical Engineering Research (ICMER 2013), pp. 1-25. Universiti Malaysia Pahang.

20. Guide, ANSYS FLUENT User'S. "Release 17.0." Ansys Inc (2016).

21. A. B. M. F. Bhuiyan and R. Hey. (2007) "Computation of three-dimensional flow field created by weir-type structures." Engineering Applications of Computational Fluid Mechanics 1, no. 4: 350-360. https://doi.org/10.1080/19942060.2007.11015205
22. D. Guan, B. W. Melville, and H. Friedrich. (2013) "Flow patterns and turbulence structures in a scour hole downstream of a submerged weir." Journal of Hydraulic Engineering 140, no. 1: 68-76. https://doi.org/10.1061/(ASCE)HY.1943-7900.0000803

\section{AUTHOR PROFILE}

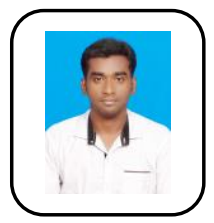

Mr. R. Karthik, completed his M.Tech in Water resources Engineering at NIT Silchar and working as a research scholar at same institute. He has published 3 research articles. Karthik is an associate member of IEI. His area of interest is Local Scour and its countermeasures at hydraulics structure and computational fluid dynamics.

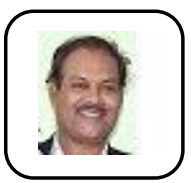

Dr. Upendra Kumar, completed his Bachelor's Degree in Civil Engineering from Bhagalpur College of Engineering in 1994 and his Master of Civil Engineering with specialization in Environmental Engineering, from Jadavpur University, Kolkata, India in 1997 and Ph. D. in Civil Engineering with specialization in Environmental Engineering, from Indian Institute of Technology, Kharagpur, India in 2005. At present he is holding the post of Associate Professor in the Department of Civil Engineering at National Institute of Technology, Silchar. He has published 66 number of Research Paper in total out of which 26 are in reputed Journals, 04 in edited books and the rest in Conferences. He has more than 600 Citation in International Journals. Current and previous research interests area includes Environmental Engineering; Water and Wastewater Engineering; Air and Noise Pollution; Adsorption technology. Dr. Kumar is also the Fellow Member of International Congress of Environmental Research (F.I.C.E.R.), Senior Member of IACSIT, Senior Member of Asia-Pacific Chemical, Biological\& Environmental Engineering Society (APCBEES) and Life Member of Institution of Engineers (India). Dr. Kumar is also associated with some Important International Journals as Referee and Reviewer.

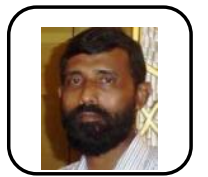

Dr. Abdul Karim Barbhuiya is currently holding the post of Professor, Civil Engineering Department, National Institute of Technology, Silchar. He joined this Institute in the year 1994 as lecturer and thereafter completed his Ph.D. from IIT Kharagpur in 2003. His area of interest includes Local scour around obstructions, Riverbank erosion, Sediment transport, Watershed management. He has published more than 20 research papers in reputed international journals (SCI \& Web of Science). 